\title{
Functional constipation in children: challenges and solutions
}

This article was published in the following Dove Press journal:

Pediatric Health, Medicine and Therapeutics

9 March 2017

Number of times this article has been viewed

\section{Elvira Ingrid Levy* \\ Roel Lemmens* \\ Yvan Vandenplas \\ Thierry Devreker}

Kidz Health Castle, UZ Brussel,Vrije Universiteit Brussel, Brussels, Belgium

*These authors contributed equally to this work
Correspondence: Yvan Vandenplas Kidz Health Castle, UZ Brussel, Vrije Universiteit Brussel, Laarbeeklaan I0I, 1090 Brussels, Belgium

Tel +32 24775794

Email yvan.vandenplas@uzbrussel.be
Abstract: This review intends to update what is known about and what is still a challenge in functional constipation (FC) in children regarding epidemiology, pathophysiology, diagnosis, and management. Although FC is a common childhood problem, its global burden remains unknown as data from parts of the world are missing. Another problem is that there is a large variation in prevalence due to differences in study methods and defining age groups. The pathophysiology of FC remains unclear to date but is probably multifactorial. Withholding behavior is likely to be the most important factor in toddlers and young children. Genetics may also play a role since many patients have positive family history, but mutations in genes associated with FC have not been found. Over the past years, different diagnostic criteria for FC in infants and children have been proposed. This year, Rome IV criteria have been released. Compared to Rome III, it eliminates two diagnostic criteria in children under the age of 4 who still wear diapers. Physical examination and taking a thorough medical history are recommended, but other investigations such as abdominal radiography, transabdominal recto-ultrasonography, colonic transit time, rectal biopsies, and colon manometry are not routinely recommended. Regarding treatment, guidelines recommend disimpaction and maintenance therapy with polyethylene glycol (PEG) with or without electrolytes. But experience shows that acceptability, adherence, and tolerance to PEG are still a challenge. Counseling of parents and children about causes of FC is often neglected. Recent studies suggest that behavior therapy added to laxative therapy improves the relief of symptoms. Further homogeneous studies, better-defined outcomes, and studies conducted in primary care are needed.

Keywords: functional constipation, children, epidemiology, pathophysiology, diagnostics, treatment, recurrent abdominal pain

\section{Introduction}

Constipation is an underestimated but common health problem worldwide, decreasing the quality of life. Children with constipation will quite often visit a general practitioner or pediatrician. These children are also regularly seen on the emergency ward or even admitted to the hospital for treatment. Therefore, constipation can represent a high cost for the global health system.

Constipation, especially in children, leads to several diagnostic and therapeutic challenges. This review gives an update of what is known and what is still a challenge in children having functional constipation (FC) regarding epidemiology, pathophysiology, diagnosis, and management. This updated review stresses the emotional and physical suffering of children with FC and highlights the impact of adequate management. 


\section{Epidemiology}

FC is a common childhood problem with varied prevalence between geographic regions. ${ }^{1}$ In North and South America, the prevalence (including infants-adolescents) ranges between $10 \%$ and $23 \%,{ }^{1-5}$ while in Europe (only including children) figures between $0.7 \%$ and $12 \%$ are reported. ${ }^{1}$ In Asia (including infants-adolescents), the prevalence is estimated between $0.5 \%$ and $29.6 \% .^{1,6-8}$ While constipation occurs in all continents, currently there is a lack of prevalence data in children from Africa and Oceania.

The prevalence varies according to age groups. The peak incidence of constipation occurs between 2 and 4 years of age, when the potty training starts. A recent systematic review found that the median prevalence of constipation in children was $12 \% .{ }^{1}$ The incidence of constipation reported in infants varies between $0.05 \%$ and $39.3 \%$, but based on expert consensus the prevalence is estimated at $15 \%$. At this age, feeding is a major contributing factor. ${ }^{9}$ Unlike as in the adult population, where constipation is more prominent in females, ${ }^{1}$ data on gender differences in infants and adolescents are unclear. ${ }^{2,4,6,8,10}$

Many factors contribute to the large variation in the reported prevalence of constipation in children such as differences in definition, differences in age groups, and methodology. ${ }^{11}$

\section{Pathophysiology}

Constipation is defined as FC if there is no underlying organic cause, what is the case in up to $95 \%$ of children. ${ }^{12}$ In the $5 \%$ with organic cause, the etiology varies from Hirschsprung disease, anorectal malformations, neuromuscular disease, metabolic to endocrine disorders.

The pathophysiology of FC in children remains unclear but is multifactorial. The most common mechanism for developing FC, especially in young children, is withholding behavior, often starting after a painful-frightening bowel movement. ${ }^{13}$ The stools remain in the rectum, the rectal mucosa reabsorbs water from the retained stools, which become more difficult to evacuate. This vicious circle can lead to fecal impaction, sometimes to overflow fecal incontinence, loss of rectal sensation, and ultimately, loss of normal urge to defecate. ${ }^{14}$

In a subgroup of children, FC can be due to slow transit. The interstitial cells of Cajal play an important role in the motility of the gut. These cells can be regarded as pacemakers that generate peristalsis in the gut. Many publications report consistent histological findings in children with all forms of constipation of a low number of interstitial cells of Cajal, although the normal number of interstitial cells of Cajal in healthy children remains unclear. ${ }^{15}$ Slow transit constipation is also associated with low levels of substance $P$ and vasoactive intestinal peptide in the right transverse colon, but these findings did not help to develop new therapeutic options. ${ }^{16}$

Many patients with FC have a positive family history of $\mathrm{FC}$, suggesting that genetic factors may play a role, although mutations have not been discovered. ${ }^{17} \mathrm{FC}$ is associated with neurodevelopmental disorders such as autism spectrum disorders (ASDs). This physio-pathological pathway remains unclear but is suggested to be due to a lack of adequate behavior in response to a sense of defecation urge. ${ }^{18,19}$ Genetics, with the presence of contiguous gene syndromes resulting from mutations in multiple adjacent genes, dysbiosis, and atypical sensory processing have also been suggested as possible explanations for the consistent link between ASD and FC.

There is an association between parental child-rearing attitudes and FC. Higher and lower scores on the autonomy attitude scale are associated with decreased defecation frequency and increased fecal incontinence; this association was more clearly found in children over 6 years of age. ${ }^{20}$ Stressful life events, such as (sexual) abuse, may also play a role in the development of FC. ${ }^{21}$

\section{Diagnostic criteria}

In 1999, the Rome II criteria were approved but later seen as too restrictive by subdividing some pathologies such as $\mathrm{FC}$ and functional fecal retention and defining the minimum duration of symptoms at 3 months. ${ }^{11}$

The Paris Consensus on Childhood Constipation Terminology (PACCT) group redefined the definition of FC in children. A study comparing PACCT and Rome II found that only 53 of 126 (42.1\%) children were recognized as constipated by the Rome II criteria, compared with the PACCT criteria. This difference in incidence was mainly because in Rome II the presence of retentive posturing together with less than two bowel movements per week since at least 3 months were needed for the diagnosis of FC. ${ }^{11}$ In the Rome III criteria, published in 2006, mainly based on the PACCT definition (Table 1) replaced the "encopresis" and "soiling" by "fecal incontinence."11

According to Rome III, two of six criteria are needed for the diagnosis of FC and two age groups are defined. One group of $>4$ years of developmental age until adolescence and a second group of children under 4 years of developmental age. Two criteria need to be present for at least 1 month in the youngest group, whereas in older children symptoms need to be present since at least 2 months. 





Some studies compared Rome II and III criteria and reported contradicting findings. FC was more frequently diagnosed with Rome II (32.4\%) than III (18.2\%) in infants and toddlers visiting a well-baby clinic in Thailand. ${ }^{22}$ One of the reasons for this difference lies in the fact that children with painful defecation associated with evacuation of hard stools were excluded from Rome III. In Rome III, both aspects are grouped together, which means that one criterion more is needed for the diagnosis of FC. This may delay diagnosis. ${ }^{22}$ Another criterion that made the definition too restrictive for young children in Rome III is the "large-diameter stools that could obstruct the toilet." $22 \mathrm{~A}$ chart review conducted in outpatient children (mean age $6.3 \pm \mathrm{SD}$ ) referred to a tertiary center showed that $87 \%$ of older children had constipation according to Rome III and only $43 \%$ children while using Rome II $(p<0.001)$. This was attributed to the Rome III criteria "fecal incontinence of at least one episode a week" and "large-diameter stools that may obstruct a toilet." These symptoms are usually more frequent in severe chronic constipation, mostly seen in tertiary centers. Only $10 \%$ of the young population presents these symptoms. ${ }^{22,23}$

Recently, the new Rome IV criteria have been released. The criteria for younger children (age group $0-4$ years mental age) have been adjusted. Children who are not toilet trained do not need to fulfill two additional criteria to be diagnosed with FC. The eliminated criteria are "large-diameter stools that may obstruct a toilet" and "fecal incontinence with at least one episode a week." The first criterion is not applicable for this age group, but the other criterion seems also obvious to exclude since you cannot speak of fecal incontinence if toilet training is not achieved. Next, the duration of symptoms has been shortened from 2 to 1 month, for the age group from 4 years until adolescence. Although Rome IV criteria are proposed as the new golden standard, it has to be evaluated like all the other definitions. Rome criteria are especially relevant to select patients with a comparable degree of FC for clinical trials and might be less useful for the diagnosis in clinical practice. New studies are needed to evaluate the usefulness of Rome IV criteria in diagnosing FC in every day care. Until now, studies were conducted to evaluate the criteria, only in unselected young children. Therefore, studies, evaluating Rome IV criteria, conducted in an unselected population of all ages are needed.

\section{Medical history}

Taking a medical history is the first step in the diagnosis of children with FC. The medical history should contain information on many factors such as age of onset, passage of first meconium, frequency and consistency of stools, abdominal pain, fecal incontinence, withholding behavior, dietary history, vomiting, and weight loss. As mentioned before, stressful life events, neurodevelopmental delay/problems, and search for a positive family history for gastrointestinal disease should be evaluated. The Bristol Stool Scale has become the preferred and standardized method to describe stool consistency. ${ }^{24}$ However, the scale is not adapted for non-toilet-trained children. The Amsterdam Stool Scale was developed for infants but is complex for routine use as it includes 18 different pictures. ${ }^{25,26}$ A Brussels Infant Stool Scale is under development.

A physical examination in children with FC should always include growth parameters, an abdominal examination, inspection of the perianal region, and examination of the lumbosacral region.

\section{Rectal digital examination}

According to the European Society of Pediatric Gastroenterology, Hepatology and Nutrition (ESPGHAN) and North American Society of Pediatric Gastroenterology, Hepatology and Nutrition (NASPGHAN) guidelines, a rectal digital examination is not always recommended to make the diagnosis of FC. ${ }^{12}$ On the contrary, in the Rome III and IV definition, it is stated that the presence of a large fecal mass in the rectum is a criterion for FC. Therefore, ESPGHAN and NASPGHAN concluded that if only one of the Rome criteria is present and the diagnosis of FC is uncertain, a digital examination is recommended. Also, in patients with intractable constipation or in patients with alarm signs, a digital rectal examination remains necessary. An inspection of the anal region is indispensable to evaluate the presence of scars, hemorrhoids, perianal feces, and fissures. ${ }^{27}$

\section{Laboratory testing}

In the absence of alarm signs, laboratory screening for hypothyroidism, celiac disease, vitamin D status, hypercalcemia, or cow milk allergy is not recommended. ${ }^{12}$ However, in a young patient with long-lasting complaints of constipation, a trial with a cow milk-free diet for 2-4 weeks can be considered. Although the pathogenic mechanism remains unclear, it has been hypothesized that an allergic inflammation of the internal sphincter may lead to an increased anal pressure at rest. ${ }^{28}$

\section{Abdominal radiography}

The ESPGHAN and NASPGHAN guidelines do not recommend a diagnostic abdominal radiography, which is a widely accessible and cheap procedure. A major disadvantage is the radiation exposure for the patient. Several scoring systems have been developed to assess the amount of fecal load and 
to diagnose constipation. Nevertheless, systematic reviews showed that there is no diagnostic association between clinical symptoms of constipation and fecal load on abdominal radiography. ${ }^{29,30}$ There was also poor interobserver reproducibility of the scoring systems. ${ }^{31}$

An abdominal radiography can also lead to misdiagnosis. A retrospective cohort study showed that 1 in 200 children that received a diagnosis of FC based on an abdominal radiography required a surgical or radiological intervention within 7 days. The missed diagnoses were potentially life-threatening and included perforated appendicitis, intussusception, brain tumor, leukemia, and volvulus. ${ }^{32}$

In some rare conditions, an abdominal radiography may still be of some benefit such as in the presence of psychological factors that limit the use of a digital rectal examination such as suspicion of sexual abuse or in very anxious children. When abdominal palpation is less reliable, like in extremely obese patients, an abdominal radiography can be helpful. ${ }^{27}$

\section{Transabdominal rectal ultrasonography}

Since rectal digital examination and abdominal radiography have both limitations, ultrasound is considered an alternative technique. Burgers et al compared transabdominal rectal ultrasonography and digital rectal examination, and found a positive correlation in $80 \%$ of the patients. ${ }^{27}$ This study also showed that the determination of a cut-off value for the rectal diameter is very difficult. A cut-off value of $30 \mathrm{~mm}$ induces a major overlap between children with FC and healthy controls. There seems to be a logic relation between defecation and changes in rectal diameter, so before performing a transabdominal rectal ultrasonography, the patient should be asked for defecation signals. ${ }^{33}$ For a reliable ultrasonography, an experienced performer is capital. Because of these limitations, ESPGHAN and NASPGHAN guidelines stated that rectal ultrasound is not routinely recommended to diagnose FC. ${ }^{12}$

\section{Colonic transit time}

Colonic transit time can be used to determine the colonic motility. There is no recommendation to use colonic transit time for the diagnosis of FC. Colonic transit time can be used in unclear cases to distinguish between $\mathrm{FC}$ and functional non-retentive fecal incontinence. ${ }^{12,29}$

\section{Other investigations}

If the constipation remains refractory to medical treatment, more specialized examinations in a referral center should be considered.
An anorectal manometry can be a useful screening tool in older children with untreatable constipation with suspicion of Hirschsprung disease. ${ }^{12}$ An abnormal recto-anal inhibitory reflex is an indication to perform a rectal suction biopsy, which is the gold standard for diagnosing Hirschsprung disease.

A colonic manometry should only be performed in patients when therapies failed and surgery is considered. Colonic manometry can help to distinguish between children with normal colon motility and those with colonic neuromuscular disorders. ${ }^{34}$

\section{Treatment}

The recommendation for the management of FC includes a normal intake of fibers and fluids, normal physical activity, and an additional pharmacologic treatment for fecal disimpaction followed by a pharmacologic maintenance therapy. ${ }^{12}$

Disimpaction therapy can be done antegrade by oral route by simple drinking or through a nasogastric tube or retrograde by anal route. Oral polyethylene glycol (PEG) with or without electrolytes (1-1.5 g/kg for 3-6 days) is the first choice. There is no difference in efficacy for fecal disimpaction between PEG and enema. ${ }^{12,35,36}$ PEG is associated with a higher frequency of fecal incontinence, whereas enemas are associated with more abdominal cramps and fear. ${ }^{12,35}$ Both adverse effects can make it difficult for children to accept and adherence to this therapy. Two studies have compared the distress level of disimpaction with enemas in comparison to PEG. One study found no difference in distress, ${ }^{35}$ whereas in the other study, the children were more "upset" if they were in the enema group, when administered at the emergency department. ${ }^{36}$ It was also shown that if a child had previous experience with enemas, that enemas can be administrated at home. ${ }^{35}$

Concerning maintenance therapy, the guidelines recommend the use of PEG with or without electrolytes at lower dosages $(0.2-0.8 \mathrm{~g} / \mathrm{kg}){ }^{12}$ Despite the fact that children may not like the taste of PEG, especially with electrolytes, few studies have evaluated the acceptability and adherence to PEG treatment. Only one study compared PEG with electrolytes and without flavors to PEG without electrolytes and added flavors. The acceptability was higher for PEG without electrolytes as parents found it easier to administer (96\% vs. $52 \% ; p<0.001)$, and children found the PEG without electrolytes "good" tasting ( $42 \%$ vs. $2 \% ; p<0.001)$. But after 4 weeks, no significant difference in adherence (98\% vs. $88 \%$; $p<0.062$ ) was found. ${ }^{37}$

A systematic review showed that only $61 \%$ of children could be taken off laxatives 6-12 months after starting 
treatment. ${ }^{38}$ Children with chronic constipation, referred to tertiary care center, were followed for $>10$ years and showed that despite intensive treatment strategies only $80 \%$ reached good clinical outcomes by the age of 16 . This poor outcome was associated with older age at onset, longer delay between symptom onset, and first visit to a pediatric gastroenterology clinic. ${ }^{39}$

Many parents might be hesitating to administer medication for a long time because of fear for a rebound effect or addiction. ${ }^{39,40}$ PEG during 6 months is considered safe by analyzing adverse events such as nausea, bloating, and biochemical changes such as sodium levels. ${ }^{40-44}$

Since acceptability and adherence are not optimal, it is necessary to seek for better strategies. To reassure parents for long-term safety of PEG, longer follow-up studies are needed. Although PEG is the recommended therapy for maintenance, studies are heterogenic (e.g., interventions, definition of FC, and outcome measures) with biases. ${ }^{12}$ This was confirmed in the Cochrane systematic review of $2016 .{ }^{41}$ The optimal dosage of PEG also needs further investigation and longer follow-up. A very important, but frequently overlooked problem, is the best primary endpoint. If treatment is aimed at Rome criteria, children can be considered cured, while still suffering from one of the six criteria. An optimal treatment, for every clinician, should aim a symptom-free patient.

Although guidelines for FC recommend the use of an osmotic laxative such as PEG for maintenance and disimpaction, some countries have no access to PEG. Guidelines recommend an alternative osmotic laxative such as lactulose if PEG is not available. Lactulose has been more and better evaluated than milk of magnesia (magnesium hydroxide) or mineral oil and is safe for all ages. ${ }^{45}$

All studies and meta-analyses show that PEG is superior to lactulose in all aspects: number of stools per week (MD 0.70 , 95\% CI 0.10 to 1.31 ), no need of additional laxative therapy (18\% vs. $31 \%$ ) and successful disimpaction $(100 \%-80 \%, p=0.04)$. There is no statistically significant difference between PEG and lactulose for any of the adverse events including fecal incontinence flatulence, abdominal pain, nausea, or abdominal bloating.

Lactulose is not only inferior to PEG but also to milk of magnesia (MD $-1.51,95 \% \mathrm{CI}-2.63$ to -0.39 ) and liquid paraffin (MD 4.94, 95\% CI 4.28 to 5.61) in one small study with 50 inclusions. However, this was only for the number of stools per week without information on successful disimpaction. Lactulose had no significant difference in success rate compared with dietary fiber, Senna anthraquinones (stimulant laxative), lactitol, or hydrolyzed guar gum (both osmotic laxatives). However, this is based on one study each. It is also important to mention that there are no studies comparing lactulose to placebo. ${ }^{41}$ Knowing that these studies are extremely heterogeneous and the time of follow-up mostly very short, it is difficult to comment on the maintenance and disimpaction treatment with lactulose. The recommended dosage of lactulose is $1-2 \mathrm{~g} / \mathrm{kg}$ once or twice a day. ${ }^{12,41}$

Concerning other laxatives PEG was superior to placebo, milk of magnesia, mineral oil (liquid paraffin), dietary fibers mix, and flixweed (a traditional Persian medicinal plant). However, for milk of magnesia, there was no significant difference in success of disimpaction. ${ }^{41}$

For liquid paraffin, a meta-analysis of two studies $(n=287)$ was done without favorable results. ${ }^{41}$ Concerning liquid paraffin, another review mentions annoying side effects such as leakage of oily secretions from the anus, causing irritation or itching of the skin, and staining of cloths or furniture. Low serum levels of fat-soluble vitamins absorption have also been described. ${ }^{46}$

The guidelines mention also stimulant laxatives, such as diphenylmethanes: sodium picosulfate and bisacodyl. The latest Cochrane meta-analysis evaluates the management of FC with both osmotic and stimulant laxatives, but the majority of the included studies used osmotic laxatives. ${ }^{41}$ No studies, as far as we know, have compared bisacodyl and sodium picosulfate with PEG or lactulose or other laxatives in children for the maintenance or disimpaction treatment.

Other pharmacological therapies such as rectal laxatives/ enema with fecal softeners (sodium docusate and sodium phosphate), recent developed molecules (lubiprostone, linaclotide, and prucalopride), and probiotics and prebiotics are not (yet) recommended by any guideline.

Only one study, as far as we know, compared sodium docusate enema to PEG and one study compared sodium docusate enema to free fatty acids suppositories for the disimpaction in children. Successful disimpaction was equal for sodium docusate enema $(80 \%)$ and PEG $(68 \% ; p=0.28) .{ }^{35}$ For the high-doses free fatty acid suppositories, no difference with the enema ( $81 \%$ vs. $88 \%$ ) was found, and the authors believe that it could be an important addition to the treatment options that are currently available. ${ }^{47}$ Sodium phosphate was compared to milk and molasses enemas in one study in children and reported no statistically significant differences for safety and effectiveness. ${ }^{48}$ However, one study with sodium phosphate enema reported hyperphosphatemia in 35 cases, of which $80 \%$ recovered without problems. The authors state that it is better not to administrate sodium phosphate enema in children having an underlying gastrointestinal or renal abnormality. ${ }^{49}$ 
One study was conducted in children with lubiprostone but was not fitting the inclusion criteria for this review. ${ }^{50}$ For linaclotide, no studies were performed in children and for prucalopride two studies were conducted of which one is an open-label pilot study and one multicenter RCT double-blind study. ${ }^{51}$ The pilot study concluded after 8 weeks of treatment that there was an increase in bowel movement frequency and a reduction in incontinence in $55 \%$ of patients $(n=38)$ and save to give to children. The multicenter study concluded that it was well tolerated but demonstrated no difference with placebo for spontaneous bowel movements/week (60.4\% vs. $55.1 \%)$ and adverse events $(69.8 \%$ vs. $60.7 \%))^{52}$

A recent systematic review on the use of probiotics and/ or prebiotics concluded that most studies were at high risk of bias and did not show a significant effect on defecation frequency, fecal incontinence, and painful or difficult defecation. ${ }^{35,53}$ The multitude of different prebiotics and probiotics and their varying dosages used in all studies makes it almost impossible to make firm conclusions. A very severe standardization will be necessary to conduct studies for children with constipation.

Tolerance and core outcome set are another important component for effective treatment. Most studies use frequency of bowel movement and consistency of stools. But these are inherently limited in relation to the realities of clinical practice. There may be a statistically significant increase in frequency of bowel movements between study groups, but this does not give any information whether all children and their parents feel that there has been a real improvement. One study has addressed that first the inconsistency and heterogeneity in definition and outcome measurements should be solved. They propose a minimal core outcome set for clinicians to make comparison possible between the effects of different therapeutic interventions across studies. ${ }^{54}$ However, most used outcomes in studies do not correlate with the patient complains in everyday practice. A minimal core outcome for the complains of patients and their parents should be developed.

An essential aspect, that is often neglected, is counseling of parents and children about the possible causes of chronic FC and soiling. ${ }^{21,46,55-57}$ Parental child-rearing attitudes (parental high and low autonomy scores, self-pitting) are associated with defecation rate and fecal incontinence frequency, and it is advised that addressing parent's issues should be incorporated into treatment management of $\mathrm{FC} .{ }^{20}$ The recent guideline does not support behavior therapy unless children present with behavioral abnormalities. ${ }^{12}$ But, a recent metaanalysis and a Cochrane study suggest that behavior therapy added to laxative therapy may improve symptoms of children with constipation-associated fecal incontinence. ${ }^{58,59}$ Optimal treatment of FC, especially with fecal incontinence, requires a perfect relation with great empathy between the child and the practitioner. Using an external person for behavior therapy can trouble this relation. Prescribing laxatives never resolves FC completely. Every caregiver has to be able and take the time to explain, coach, motivate, and stimulate the child and his parents.

The majority of the studies evaluating management of FC are done in second or tertiary centers where children suffering from long-lasting and therapy-resistant chronic constipation, but the majority of children who experience constipation and whose parents seek medical care present themselves at primary health care. One study done in primary care has shown that after 2 months of treatment nearly $40 \%$ of constipated children remain symptomatic. ${ }^{60}$ More studies are urgently needed in primary care.

Multidisciplinary management is not incorporated into the guidelines due to a lack of proof of RCT to show some benefit. However, when several attempts of outpatient management have failed, constipation specialists often use a multidisciplinary approach. Until now, no studies were conducted evaluating this approach.

\section{In summary}

Although effective and safe treatment options have been reported in children with FC, a lot of challenges persist. Epidemiological data from some parts of the world are still missing. The physiopathological pathway remains unclear in children. A lack of adequate behavior in response to a sense for defecation is a major contributing factor. Genetics might also play a role and should be more explored. The new Rome IV criteria have adjusted some criteria, which should make it easier for the diagnosis of FC in younger children, but new studies are needed to evaluate its usefulness in everyday practice. Infants and children, not fulfilling the Rome criteria, but presenting with one of the six criteria, can be disturbed in their everyday life and also need adequate medical help. The ESPGHAN/NASPGHAN guidelines do only recommend medical history and physical examination to be performed in all infants and children with anamnestic and clinical symptoms of FC, in the absence of alarm signs. Concerning disimpaction and maintenance management of FC, PEG is recommended as a first choice. Although scientific literature systematic mention that larger homogeneous studies are needed in unselected populations. Acceptability and adherence seem to be a problem for PEG since children 
not always like the taste. Longer follow-up studies are needed for evaluation of adherence and safety of PEG. As mentioned before, in long term, tolerance is important for an effective drug treatment, but the primary outcomes, used in studies, not always correspond to the patients complains in everyday practice. A minimal core set outcome has been proposed because of inconsistency and heterogeneity in definition and outcome measurements between studies, but perhaps a minimal core outcome concerning the complains of children and their parents should be developed. The last but not least important aspect of the treatment is counseling parents and children about FC. Behavior therapy added to laxative therapy improves the outcome. ${ }^{58,59}$ More attention should be given to this approach, and it should be incorporated in guidelines. Most studies are conducted in second and tertiary centers, while the majority of patients present and are managed at the primary healthcare level.

\section{Disclosure}

The authors report no conflicts of interest in this work.

\section{References}

1. Mugie SM, Benninga MA, Di Lorenzo C. Epidemiology of constipation in children and adults: a systematic review. Best Pract Res Clin Gastroenterol. 2011;25(1):3-18.

2. Lewis ML, Palsson OS, Whitehead WE, van Tilburg MA. Prevalence of functional gastrointestinal disorders in children and adolescents. J Pediatr. 2016;177:39-43.e3.

3. Saps M, Nichols-Vinueza DX, Rosen JM, Velasco-Benitez CA. Prevalence of functional gastrointestinal disorders in Colombian school children. J Pediatr. 2014;164(3):542-545 e1.

4. Lu PL Velasco-Benítez CA, Saps M. Gender, age, and prevalence of pediatric irritable bowel syndrome and constipation in Colombia: a population-based study. J Pediatr Gastroenterol Nutr. Epub 2016 Aug 30.

5. Lu PL, Saps M, Chanis RA, Velasco-Benitez CA. The prevalence of functional gastrointestinal disorders in children in Panama: a schoolbased study. Acta Paediatr. 2016;105(5):e232-e236.

6. Zhang SC, Wang WL, Qu RB, et al. Epidemiologic survey on the prevalence and distribution of childhood functional constipation in the northern areas of China: a population-based study. Zhonghua Liu Xing Bing Xue Za Zhi. 2010;31(7):751-754. Chinese.

7. Walter HA, Hovenkamp A, Rajindrajith S, Devanarayana NM, Rajapakshe NN, Benninga MA. OP-12 prevalence of functional constipation in infants and toddlers in Sri Lanka. J Pediatr Gastroenterol Nutr. 2015;61(4):541.

8. Bhatia V, Deswal S, Seth S, Kapoor A, Sibal A, Gopalan S. Prevalence of functional gastrointestinal disorders among adolescents in Delhi based on Rome III criteria: a school-based survey. Indian J Gastroenterol. 2016;35(4):294-298.

9. Vandenplas Y, Abkari A, Bellaiche M, et al. Prevalence and health outcomes of functional gastrointestinal symptoms in infants from birth to 12 months of age. J Pediatr Gastroenterol Nutr. 2015;61(5):531-537.

10. van Tilburg MA, Hyman PE, Walker L, et al. Prevalence of functional gastrointestinal disorders in infants and toddlers. $J$ Pediatr. 2015;166(3):684-689.

11. Boccia G, Manguso F, Coccorullo P, Masi P, Pensabene L, Staiano A. Functional defecation disorders in children: PACCT criteria versus Rome II criteria. J Pediatr. 2007;151(4):394-398, 398 e1.
12. Tabbers MM, DiLorenzo C, Berger MY, et al; European Society for Pediatric Gastroenterology, Hepatology, and Nutrition; North American Society for Pediatric Gastroenterology. Evaluation and treatment of functional constipation in infants and children: evidence-based recommendations from ESPGHAN and NASPGHAN. J Pediatr Gastroenterol Nutr. 2014;58(2):258-274.

13. Mugie SM, Di Lorenzo C, Benninga MA. Constipation in childhood. Nature Rev Gastroenterol Hepatol. 2011;8(9):502-511.

14. Rajindrajith S, Devanarayana NM. Constipation in children: novel insight into epidemiology, pathophysiology and management. $J$ Neurogastroenterol Motil. 2011;17(1):35-47.

15. Knowles CH, Farrugia G. Gastrointestinal neuromuscular pathology in chronic constipation. Best Pract Res Clin Gastroenterol. 2011;25(1): $43-57$.

16. King SK, Sutcliffe JR, Ong SY, et al. Substance P and vasoactive intestinal peptide are reduced in right transverse colon in pediatric slowtransit constipation. Neurogastroenterol Motil. 2010;22(8):883-892, e234.

17. Peeters B, Benninga MA, Hennekam RC. Childhood constipation; an overview of genetic studies and associated syndromes. Best Practice Res Clin Gastroenterol. 2011;25(1):73-88.

18. Samsam M, Ahangari R, Naser SA. Pathophysiology of autism spectrum disorders: revisiting gastrointestinal involvement and immune imbalance. World J Gastroenterol. 2014;20(29):9942-9951.

19. Mazurek MO, Vasa RA, Kalb LG, et al. Anxiety, sensory over-responsivity, and gastrointestinal problems in children with autism spectrum disorders. J Abnor Child Psychol. 2013;41(1):165-176.

20. van Dijk M, de Vries GJ, Last BF, Benninga MA, Grootenhuis MA. Parental child-rearing attitudes are associated with functional constipation in childhood. Arch Dis Child. 2015;100(4):329-333.

21. Philips EM, Peeters B, Teeuw AH, et al. Stressful life events in children with functional defecation disorders. J Pediatr Gastroenterol Nutr. 2015; 61(4):384-392.

22. Osatakul S, Puetpaiboon A. Use of Rome II versus Rome III criteria for diagnosis of functional constipation in young children. Pediatr Int. 2014;56(1):83-88.

23. Burgers R, Levin AD, Di Lorenzo C, Dijkgraaf MG, Benninga MA. Functional defecation disorders in children: comparing the Rome II with the Rome III criteria. J Pediatr. 2012;161(4):615-620. e1.

24. Lewis SJ, Heaton KW. Stool form scale as a useful guide to intestinal transit time. Scand J Gastroenterol. 1997;32(9):920-924.

25. Ghanma A, Puttemans K, Deneyer M, Benninga MA, Vandenplas Y. Amsterdam infant stool scale is more useful for assessing children who have not been toilet trained than Bristol stool scale. Acta Paediatr. 2014; 103(2):e91-e92.

26. Bekkali N, Hamers SL, Reitsma JB, Van Toledo L, Benninga MA. Infant stool form scale: development and results. J Pediatr. 2009;154(4): 521-526. e1.

27. Burgers R, de Jong TP, Benninga MA. Rectal examination in children: digital versus transabdominal ultrasound. J Urol. 2013;190(2):667-672.

28. Miceli Sopo S, Arena R, Greco M, Bergamini M, Monaco S. Constipation and cow's milk allergy: a review of the literature. Int Arch Allergy Immunol. 2014;164(1):40-45.

29. Berger MY, Tabbers MM, Kurver MJ, Boluyt N, Benninga MA. Value of abdominal radiography, colonic transit time, and rectal ultrasound scanning in the diagnosis of idiopathic constipation in children: a systematic review. J Pediatr. 2012;161(1):44-50.e1-e2.

30. Benninga MA, Tabbers MM, van Rijn RR. How to use a plain abdominal radiograph in children with functional defecation disorders. Arch Dis Child Educ Pract Ed. 2016;101(4):187-193.

31. Pensabene L, Buonomo C, Fishman L, Chitkara D, Nurko S. Lack of utility of abdominal $\mathrm{x}$-rays in the evaluation of children with constipation: comparison of different scoring methods. J Pediatr Gastroenterol Nutr. 2010;51(2):155-159.

32. Freedman SB, Thull-Freedman J, Manson D, et al. Pediatric abdominal radiograph use, constipation, and significant misdiagnoses. J Pediatr. 2014;164(1):83-88.e82. 
33. Modin L, Dalby K, Walsted AM, Jakobsen M. Transabdominal ultrasound measurement of rectal diameter is dependent on time to defecation in constipated children. J Paediatr Child Health. 2015;51(9):875-880.

34. Rodriguez L, Sood M, Di Lorenzo C, Saps M. An ANMS-NASPGHAN consensus document on anorectal and colonic manometry in children. Neurogastroenterol Motil. 2017;29(1).

35. Bekkali NL, van den Berg MM, Dijkgraaf MG, et al. Rectal fecal impaction treatment in childhood constipation: enemas versus high doses oral PEG. Pediatrics. 2009;124(6):e1108-e1115.

36. Miller MK, Dowd MD, Friesen CA, Walsh-Kelly CM. A randomized trial of enema versus polyethylene glycol 3350 for fecal disimpaction in children presenting to an emergency department. Pediatr Emerg Care. 2012;28(2):115-119.

37. Savino F, Viola S, Erasmo M, Di Nardo G, Oliva S, Cucchiara S. Efficacy and tolerability of peg-only laxative on faecal impaction and chronic constipation in children. A controlled double blind randomized study vs a standard peg-electrolyte laxative. BMC Pediatr. 2012;12:178.

38. Pijpers MA, Bongers ME, Benninga MA, Berger MY. Functional constipation in children: a systematic review on prognosis and predictive factors. J Pediatr Gastroenterol Nutr. 2010;50(3):256-268.

39. Bongers ME, van Wijk MP, Reitsma JB, Benninga MA. Long-term prognosis for childhood constipation: clinical outcomes in adulthood. Pediatrics. 2010;126(1):e156-e162.

40. Muller-Lissner SA, Kamm MA, Scarpignato C, Wald A. Myths and misconceptions about chronic constipation. Am J Gastroenterol. 2005; 100(1):232-242.

41. Gordon M, MacDonald JK, Parker CE, Akobeng AK, Thomas AG. Osmotic and stimulant laxatives for the management of childhood constipation. Cochrane Database Syst Rev. 2016;(8):CD009118.

42. Llerena E, Varea Calderón V, Pujol Muncunill G, et al. Comparison of the effectiveness and safety of polyethylene glycol with and without electrolytes in the treatment of chronic constipation [Comparación sobre la efectividad y seguridad del polietilenglicol con y sin electrolitos en el tratamiento del estreñimiento funcional]. An Pediatr (Barc). 2016;85(1):34-40. Spanish.

43. van Wering HM, Tabbers MM, Benninga MA. Are constipation drugs effective and safe to be used in children? A review of the literature. Expert Opin Drug Saf. 2012;11(1):71-82.

44. Bae SH. Long-term safety of PEG 4000 in children with chronic functional constipation: a biochemical perspective. Korean J Pediatr. 2010;53(7):741-744.

45. Tabbers MM, DiLorenzo C, Berger MY, et al. Evaluation and treatment of functional constipation in infants and children: evidence-based recommendations from ESPGHAN and NASPGHAN. J Pediatr Gastroenterol Nutr. 2014;58(2):258-274.

46. Koppen IJ, Lammers LA, Benninga MA, Tabbers MM. Management of functional constipation in children: therapy in practice. Paediatr Drugs. 2015;17(5):349-360.
47. Ormarsson OT, Asgrimsdottir GM, Loftsson T, Stefansson E, Lund SH, Bjornsson ES. Free fatty acid suppositories are as effective as docusate sodium and sorbitol enemas in treating constipation in children. Acta Paediatr. 2016;105(6):689-694.

48. Hansen SE, Whitehill JL, Goto CS, Quintero CA, Darling BE, Davis J. Safety and efficacy of milk and molasses enemas compared with sodium phosphate enemas for the treatment of constipation in a pediatric emergency department. Pediatr Emerg Care. 2011;27(12):1118-1120.

49. Ladenhauf HN, Stundner O, Spreitzhofer F, Deluggi S. Severe hyperphosphatemia after administration of sodium-phosphate containing laxatives in children: case series and systematic review of literature. Pediatr Surg Int. 2012;28(8):805-814.

50. Hyman PE, Di Lorenzo C, Prestridge LL, Youssef NN, Ueno R. Lubiprostone for the treatment of functional constipation in children. J Pediatr Gastroenterol Nutr. 2014;58(3):283-291.

51. Winter HS, Di Lorenzo C, Benninga MA, et al. Oral prucalopride in children with functional constipation. J Pediat Gastroenterol Nutr. 2013; 57(2):197-203.

52. Mugie SM, Korczowski B, Bodi P, et al. Prucalopride is no more effective than placebo for children with functional constipation. Gastroenterology. 2014;147(6):1285-1295. e1.

53. Koppen IJ, Benninga MA, Tabbers MM. Is There a role for pre-, proand synbiotics in the treatment of functional constipation in children? A systematic review. J Pediatr Gastroenterol Nutr. 2016;63 (Suppl 1): S27-S35.

54. Kuizenga-Wessel S, Heckert SL, Tros W, van Etten-Jamaludin FS, Benninga MA, Tabbers MM. Reporting on outcome measures of functional constipation in children-a systematic review. J Pediatr Gastroenterol Nutr. 2016;62(6):840-846.

55. van der Plas RN, Benninga MA, Taminiau JA, Buller HA. Treatment of defaecation problems in children: the role of education, demystification and toilet training. Eur J Pediatr. 1997;156(9):689-692.

56. van Dijk M, Benninga MA, Grootenhuis MA, Last BF. Prevalence and associated clinical characteristics of behavior problems in constipated children. Pediatrics. 2010;125(2):e309-e317.

57. Borowitz SM, Cox DJ, Sutphen JL, Kovatchev B. Treatment of childhood encopresis: a randomized trial comparing three treatment protocols. J Pediatr Gastroenterol Nutr. 2002;34(4):378-384.

58. Freeman KA, Riley A, Duke DC, Fu R. Systematic review and metaanalysis of behavioral interventions for fecal incontinence with constipation. J Pediatr Psychol. 2014;39(8):887-902.

59. Brazzelli M, Griffiths PV, Cody JD, Tappin D. Behavioural and cognitive interventions with or without other treatments for the management of faecal incontinence in children. Cochrane Database Syst Rev. 2011; (12):CD002240.

60. Borowitz SM, Cox DJ, Kovatchev B, Ritterband LM, Sheen J, Sutphen J. Treatment of childhood constipation by primary care physicians: efficacy and predictors of outcome. Pediatrics. 2005;115(4):873-877.
Pediatric Health, Medicine and Therapeutics

\section{Publish your work in this journal}

Pediatric Health, Medicine and Therapeutics is an international, peerreviewed, open access journal publishing original research, reports, editorials, reviews and commentaries. All aspects of health maintenance, preventative measures and disease treatment interventions are addressed within the journal. Practitioners from all disciplines are invited to submit their work as well as healthcare researchers and patient support groups. The manuscript management system is completely online and includes a very quick and fair peer-review system. Visit http://www.dovepress.com/ testimonials.php to read real quotes from published authors. 